\title{
PERCEPÇÃO DOS PRODUTORES FRENTE À RASTREABILIDADE BOVINA: ESTUDO COMPARATIVO ENTRE BRASILE CHILE
}

\author{
PERCEPTION OF PRODUCERS FACING THE BOVINE TRACEABILITY: COMPARATIVE \\ STUDY BETWEEN BRAZIL AND CHILE
}

\author{
Viana, J.G.A ${ }^{1 *}$, Cartes, G.S. ${ }^{1}$, Fornazier, A. ${ }^{1}$, Spohr, G. ${ }^{1}$ e Silva, T.N. da ${ }^{1}$
}

${ }^{1}$ Universidade Federal do Rio Grande do Sul. Programa de Pós-Graduação em Agronegócios. Porto AlegreRS. Brasil. *joaogaribaldi@brturbo.com.br

\section{Palavras chave adicionals}

Carne bovina. Cadeias produtivas. Certificação.

\section{RESUMO}

O objetivo do presente trabalho foi analisar, de forma comparativa, a aplicabilidade e a percepção dos produtores de Dom Pedrito (Brasil) e Cunco e Vilcun (Chile) frente ao sistema de rastreabilidade bovina. O universo da pesquisa constituiu-se de dez produtores dos municípios de Cunco e Vilcun, e dez produtores do município de Dom Pedrito (Brasil). Constatou-se que os produtores pesquisados do Chile cumprem com grande parte das características operacionais de manejo, manutenção de registros e instalações do rebanho bovino, enquanto os produtores pesquisados no Brasil apresentam carências principalmente na manutenção de registros dos animais rastreados. $\mathrm{Na}$ percepção dos produtores pesquisados do Chile, a rastreabilidade influencia positivamente as características de manejo e gestão, ao contrário dos produtores pesquisados no Brasil que acreditam na influência mais intensa da rastreabilidade sobre as características de comercialização dos bovinos.

\section{SUMMARY}

The objective of this study is to examine, in a comparative way, the applicability and the perception of the producers of Dom Pedrito (Brazil) and Cunco and Vicun (Chile) facing the cattle traceability system. The universe of the survey consisted of ten producers in the municipalities of Cunco and Vilcun, and ten producers in the municipality of Dom Pedrito (Brazil). It was found that producers surveyed in Chile to carry out most

Recibido: 13-4-09. Aceptado: 12-5-10.

\section{ADDITIONAL KEYWORDS}

Beef meat. Certification. Production chains.

of the operational characteristics of management, maintenance of records and infrastructure of the cattle herd, while the producers surveyed of the Brazilian case presents lack mainly in the maintenance of records of animals. In Chilean perception, the traceability positively influences the characteristics of management and administration, unlike the case of Brazilian who producers surveyed believe in more intense influence of traceability on the characteristics of the market cattle.

\section{INTRODUÇÃO}

A globalização tornou o setor pecuário cada vez mais dinâmico no Brasil e no Chile. Para a inserção em um mercado cada vez mais competitivo, a bovinocultura dos dois países necessita ser tratada com enfoque empresarial, utilizando-se de ferramentas de gestão econômico-produtivas. Segundo Neves et al. (2001), o sistema agroalimentar tem passado por mudanças estruturais profundas e a atividade pecuária tem deixado de ser uma exploração com forte componente especulativo, passando a exigir ganhos de eficiência em todo o processo.

A segurança e a qualidade dos alimentos estão ganhando expressiva atenção e cuidados por parte dos consumidores, estimulados por percepções negativas como a 
crise da vaca louca (bovine spongiform encephalopathy - BSE), a polêmica sobre os organismos geneticamente modificados (OGMs), os riscos de proliferação da influenza aviária (H5N1) e demais problemas gerados pela contaminação de alimentos (Leonelli e Toledo, 2006).

Para recuperar a confiança dos consumidores, os agentes da cadeia de suprimento de carne bovina estão trabalhando para elevar os padrões de segurança. Oliveira Neto (2004) argumenta que, devido à necessidade de mudanças na cultura dos produtores, inicia-se a migração da clássica propriedade rural para uma empresa rural, processo no qual exige que o produtor desenvolva novos conhecimentos tornando-se um gestor do seu negócio para desenvolver competências e garantir a sua sobrevivência por meio do desenvolvimento e da lucratividade.

Neste sentido, a rastreabilidade bovina surgiu para cumprir com as exigências dos principais países importadores de carne do Brasil e do Chile, elevando a segurança alimentar, desenvolvendo competências, prometendo agregação de valor e melhorias na gestão da empresa rural. Desta forma, tornam-se relevantes estudos de caso que busquem comparar a aplicabilidade e a percepção de produtores rurais, de diferentes localidades, frente às possíveis vantagens e/ou desvantagens da rastreabilidade bovina, em especial, quando se trata de casos onde o programa de rastreabilidade é voluntário (Brasil) e obrigatório (Chile). Portanto, o objetivo do presente trabalho é analisar, de forma comparativa, a aplicabilidade e a percepção dos produtores de Dom Pedrito (Brasil) e Cunco e Vilcun (Chile) frente ao sistema de rastreabilidade bovina.

\section{MATERIALE MÉTODOS}

O presente estudo utilizou-se da abordagem mista de pesquisa, a qual se analisa dados qualitativos e quantitativos, a partir da técnica de pesquisa de estudo de caso. O universo da pesquisa constituiu-se de dez produtores dos municípios de Cunco e Vilcun, pertencentes à Região de La Araucanía, Chile e dez produtores do município de Dom Pedrito, pertencente à Região da Campanha, Rio Grande do Sul, Brasil.

O instrumento de pesquisa utilizado para a realização do estudo foi à entrevista com roteiro semi-estruturado, aplicada em vinte pecuaristas, no período de janeiro e fevereiro de 2009, constituída de questões abertas e de múltipla escolha, divididas em duas etapas de coleta de dados:

a) Aplicabilidade: três questões de múltipla escolha em torno do grau de utilização da rastreabilidade bovina. Escolha entre afirmativo ou negativo para vinte e sete afirmações referentes a três categorias operacionais da rastreabilidade bovina nas propriedades: manutenção de registros, manejo dos animais e instalações do rebanho, categorias baseadas nas exigências das normativas da rastreabilidade bovina do Brasil e Chile.

b) Percepção: questão fechada baseada em uma escala numérica de 1 a 10 , na qual os produtores entrevistados selecionam o grau de influência da rastreabilidade bovina sobre treze itens técnico-produtivos referentes a manejo, gestão e comercialização dos animais, considerando que 1 refere-se a nenhuma influência, e 10 refere-se a influência total da rastreabilidade sobre o item. A percepção dos produtores frente à influência da rastreabilidade foram comparados entre Brasil e Chile, por meio do teste t-Student. O nível de significância estabelecido foi de $5 \%$.

\section{RESULTADOSEDISCUSSÃO}

Os estudos de caso nas localidades de Dom Pedrito (Brasil) e Cunco e Vilcun (Chile) demonstram que a aplicabilidade da rastreabilidade bovina entre os dois países apresenta caráter variável. Evidencia-se que os produtores pesquisados na região de $\mathrm{La}$ 


\section{PERCEPÇÃO DOS PRODUTORES FRENTE À RASTREABILIDADE BOVINA}

Araucanía (Chile), fundamentalmente, aplicam a rastreabilidade bovina na totalidade do rebanho devido a obrigatoriedade do sistema de rastreamento animal. A aplicabilidade da rastreabilidade nos produtores pesquisados em Dom Pedrito (Brasil), é variável devido à voluntariedade do Serviço de Rastreabilidade da Cadeia Produtiva de Bovinos e Bubalinos (SISBOV).

Um ponto primordial na aplicabilidade da rastreabilidade bovina é operacionalização do sistema no ambiente produtivo. Constata-se que a totalidade dos produtores pesquisados da região de La Araucanía (Chile) utilizam das condições essenciais de manejo e instalações do rebanho. Em relação às características de manutenção de regis- tros, todos os produtores chilenos pesquisados cumprem com os itens operacionais, exceto com a existência de planilhas de insumos nutricionais ( $80 \%$ dos produtores) e medicamentos veterinários $(90 \%$ dos produtores).

No que tange as características operacionais da rastreabilidade bovina dos produtores pesquisados do município de Dom Pedrito (Brasil) considera-se aceitável o nível de cumprimento dos itens operacionais de manejo e instalações do rebanho, porém com médio-baixo percentual afirmativo de realização de registros.

A tabela I apresenta o grau de influência, na ótica dos produtores pesquisados, da rastreabilidade bovina sobre os itens técni-

Tabela I. Grau de influência ${ }^{1}$ da rastreabilidade bovina sobre itens referentes a manejo, gestão e comercialização de bovinos: médias comparadas pelo teste t-Student. (Degree of influence of bovine traceability on items related to handling, management and commercialization of beef cattle: averages compared by t-Student test).

\begin{tabular}{lccc}
\hline Variáveis & $\begin{array}{c}\text { Dom Pedrito } \\
\text { (Brasil) }\end{array}$ & $\begin{array}{c}\text { Cunco e Vilcun } \\
\text { (Chile) }\end{array}$ & $t$ calculado \\
\hline Manejo & & & \\
$\quad$ Melhoria do manejo produtivo & 4,50 & 8,90 & $-3,392^{*}$ \\
Padronização dos animais & 4,89 & 10,00 & $-5,447^{*}$ \\
Melhoria nos índices zootécnicos & 4,30 & 9,10 & $-5,563^{*}$ \\
Controle sanitário eficiente & 4,70 & 9,20 & $-4,559^{*}$ \\
Controle nutricional dos animais & 3,10 & 9,40 & $-7,896^{*}$ \\
Média & 4,30 & 9,32 & $-11,469^{*}$ \\
Gestão & & & \\
Gestão de custos da propriedade rural & 3,40 & 8,30 & $-4,941^{*}$ \\
Controle do inventário do rebanho & 8,80 & 9,90 & $-1,226$ \\
$\quad$ Redução dos custos de produção & 2,70 & 9,30 & $-7,582^{*}$ \\
Uso eficiente dos insumos & 4,30 & 8,80 & $-3,778^{*}$ \\
Média & 4,80 & 9,08 & $-6,910^{*}$ \\
Comercialização & & & $-1,484$ \\
Agregação de valor ao bovino & 6,50 & 4,80 & 0,164 \\
Segurança alimentar ao consumidor & 5,56 & 5,60 & 0,866 \\
Bom relacionamento com a indústria & 6,00 & 5,00 & 0,396 \\
$\quad$ Carne bovina com qualidade diferenciada & 7,30 & 6,80 & 1,427 \\
Média & 6,34 & 5,55 & \\
\hline
\end{tabular}

${ }^{1}$ Escala de 1 a 10 , sendo que 1 refere-se a nenhuma influência, e 10 refere-se a influência total da rastreabilidade bovina sobre a variável.

*Diferença significativa entre as médias a partir do teste t-Student $(p<0,05)$. 
VIANA, CARTES, FORNAZIER, SPOHRE SILVA

co-produtivos de manejo, gestão e comercialização. Para os produtores chilenos pesquisados, a rastreabilidade estimula melhorias nas características de manejo e gestão dos sistemas produtivos. Na ótica dos produtores pesquisados de Dom Pedrito (Brasil), a influência da rastreabilidade sobre as características de manejo e gestão é baixa e significativamente diferente das médias dos produtores chilenos, a um nível de 5\% de significância. Os produtores pesquisados do município de Dom Pedrito acreditam que a rastreabilidade gera maior influência sobre características de comercialização; ao contrário dos produtores pesquisados de Cunco e Vilcun no Chile, que determinaram as menores notas do quadro avaliativo às características de comercialização, porém, sem apresentar diferença significativa entre as médias das regiões.

Para os produtores pesquisados em Dom Pedrito, a principal vantagem da rastreabilidade bovina é o controle de estoque bovino e a melhor remuneração pelo bovino comercializado, ambas com cinco citações no total das entrevistas. Para os produtores chilenos pesquisados, a principal vantagem é o uso da rastreabilidade como ferramenta de gestão, com oito citações, seguido pelo controle de estoque bovino.

A principal desvantagem da rastreabilidade, tanto nos produtores pesquisados brasileiros como nos chilenos, é o elevado

\section{BIBLIOGRAFIA}

Leonelli, F.C.V. e Toledo, J.C. de. 2006. Rastreabilidade em cadeias agroindustriais: conceitos e aplicações. EMBRAPA Circular Técnica, n. 33. São Carlos.

Neves, M.F., Machado Filho, C.P., Carvalho, D.T.e Castro, L.T. 2001. Redes agroalimentares \& custo de aplicação do sistema. A mão-deobra exigida é uma desvantagem importante da rastreabilidade. Na percepção dos produtores pesquisados de Dom Pedrito (Brasil), a rastreabilidade exige demasiada mão-de-obra para aplicação. Já para os produtores de Cunco e Vilcun, a desvantagem está relacionada à demanda de mãode-obra qualificada para a execução dos registros obrigatórios e para uso das informações em ferramentas de gestão. Cabe destacar a diferente visão dos produtores pesquisados sobre o principal papel das instituições públicas e privadas no sistema de rastreabilidade bovina. No caso de Dom Pedrito é fornecer a gratuidade do sistema, enquanto no caso de Cunco e Vilcun (Chile), é dar auxilio econômico na implementação da rastreabilidade.

\section{CONSIDERAÇÕES FINAIS}

A aplicabilidade e percepção dos produtores frente à rastreabilidade bovina nos casos pesquisados apresentaram diferenças significativas. O presente estudo pesquisou produtores em apenas duas regiões particulares, com amostra pequena em relação à população. Entretanto, fica o desafio para futuras pesquisas em avaliar e comparar a percepção dos produtores frente à rastreabilidade e sua aplicação de forma mais ampla, geograficamente e populacionalmente, adicionando novas variáveis e perspectivas. marketing da carne bovina em 2010. Preços Agrícolas. pp. 7-18.

Oliveira Neto, O.J. 2004. Rastreabilidade: transformando a fazenda em empresa rural. Agroonline. Disponível em: www.agronline.com.br/ artigos/artigo. php?id=176 (01/09/07).

Archivos de zootecnia vol. 60, núm. 231, p. 828. 